\title{
The effect of chunk learning on listening comprehension
}

\author{
Abdol-Majid Mohseni $^{1}$, Amir Marzban ${ }^{2}$, Abdollah Keshavarzi ${ }^{3}$ \\ ${ }^{1}$ Department of English language, Fars Science and Research Branch, Islamic Azad University, Fars, Iran \\ ${ }^{2}$ Department of English language, Ghaemshahr Branch, Islamic Azad University, Ghaemshahr, Iran \\ ${ }^{3}$ Department of English language, Firoozabad Branch, Islamic Azad University, Iran
}

\section{Email address:}

abdolmajidmohseni@yahoo.com (Abdol-Majid M.)

\section{To cite this article:}

Abdol-Majid Mohseni, Amir Marzban, Abdollah Keshavarzi. The Effect of Chunk Learning on Listening Comprehension. International Journal of Language and Linguistics. Vol. 2, No. 5, 2014, pp. 310-316. doi: 10.11648/j.ijl1.20140205.14

\begin{abstract}
The present study is done to examine the effect of chunk learning on students' listening comprehension. Based on the nature of the study, the null hypothesis was proposed, chunk learning has no effect on (TOEFL) listening comprehension. In order to test the null hypothesis, a sample of 60 students was chosen. They were randomly put into two groups (experimental and control). Members of each group were randomly assigned to one of the following conditions; first the experimental group was given the same passages containing multiword in the passages of experimental group and the control group that we did not give them any passages in multiword. The design used for this study was a quasi experimental one. An English Language Test was administered at the beginning to ensure the homogeneity of the two groups in language proficiency. Then a pre-test was done to measure the student's knowledge of multi words. After the treatment which took 20 sessions, 30 minutes per session, the same pre-test was administered as a post-test to measure the effect of the treatment. Analysis of the calculated normality test (K-S), descriptive statistic of pre-test, paired sample t-test and independent sample t-test for experimental and control group provided us with the judgment to reject the null hypothesis. In other words, the result revealed that: chunk learning (multi words, verbs idioms and collocations) has a significant effect on listening comprehension ability.
\end{abstract}

Keywords: Chunk Learning, Iranian EFL Learners, Listening Comprehension

\section{Introduction}

Chunk learning or multi units constructions consists of a verb plus a particle, preposition or noun. Multi word units are important and vital elements of colloquial English that no one can speak, understand, figure out, perceive and listen to the conversation without fundamental knowledge of them. It is noticed as the idiomatic expression in English and collocation expression, so idioms and collocations and ability to use them suitably in context are depend on distinguishing native-like command of English. But, why do not many students use multiword in speaking or communication? The reason is that that they have more than one meaning, and it cannot be derived from separate words. It must study totally, not selectively. So if it is spoken or listened, it can be perceived easily. Listening Comprehension is at the core of Second Language Acquisition. So it is important for oral communication.

Nowadays, attention to listening in second language development is a crucial and an important topic of study in both theory and pedagogy. Riverse (1982) asserts that speaking does not of itself constitute communication unless what is said is comprehended by listener. Teaching the comprehension is therefore of primary significance if the communicative aim is to be reached.

This study intends to investigate chunk learning: multiword units, collocations and its effects on Listening Comprehension to offer some insights into the study and application of it in English Language teaching (ELT). The concept of Chunk Learning has been widely introduced and discussed as the teaching responsibilities in Listening Comprehension. It has been paid more attention to for the sake of improving Listening Comprehension. Therefore, a comprehensive discussion of the concept is importance for a better understanding and application of chunk learning.

One of the most widely accepted proposed explanatory mechanisms is learning based on prediction.

Pioneering work in the 1940 s and 1950s suggested that the concept of 'chunking' might be important in many processes of perception, learning and cognition in humans 
and animals (Gobet et al., 2001). The result of the study by Giroux and Rey (2009), whose results are simulated in this research, provides evidence that when chunks are learned, the subunits making up these chunks are forgotten unless they are refreshed independently (cited in French et al., 2011). This would imply that chunks are encoded as atomic entities rather than as associations between their constituent elements. This process, known as 'lexicalization', means that a chunk, once fully formed, is thereafter treated as an indivisible word, causing any words within it to be overlooked.

Mendelsohn (1998) notes a gap between the interests of listening researchers and classroom practitioners in that classroom materials do very little to develop metacognitive knowledge through raising learners' consciousness of listening processes. It is imperative to teach students how to listen. This shifts the emphasis of listening practice from product to process and the responsibility of learning from the teacher to the student, thereby helping students become self-regulated learners. Research has demonstrated that adults spend $40-50 \%$ of communication time listening (Gilman \& Moody, 1984).

\section{Review of the Related Literature}

\subsection{Research Background}

Perruchet and Pacteau (1990) presented convincing empirical evidence that simple associative learning can drive the formation of chunks and chunk-fragments. Infant initially focused largely on the question of how infants segment a continuous speech stream into lexical units. The raw auditory signal generated by human speech is notoriously hard to segment into words because breaks in the continuity of the signal are poorly correlated with actual word boundaries (Cole \&Jakimik, 1980).

TRACX successfully models adults' better learning of word solver part words in the context of (a) differential within-word, versus between-word, forward TPs (Perruchet \& Desaulty, 2008)in an artificial language with frequency-controlled test words and part words; (b) differential within-word, versus between-word, backward TPs (Perruchet \&Desaulty, 2008) in an artificial language with frequency-controlled test words and part words; (c) gradual forgetting of sub chunks found inside chunks (Giroux \&Rey, 2009), if these sub chunks are not independently refreshed; (d) sentence length and the fact that words become harder to extract as the length of the sentences in which they are found increases (Frank et al., 2010); and (e) vocabulary size and the fact that words become harder to extract as the number and length of the words to be extracted increases (Frank et al., 2010).

Shortly after Miller's 1956 paper, Feigenbaum and Simon (1962) date began to develop a pure and direct implementation of chunking mechanisms, known as EPAM (Elementary Perceiver and Memorizer).Listening has emerged as an important component in the process of second language acquisition (Feyten, 1991). Listening is a skill in language proficiency which can directly affect other skills and be affected by several other strategies or techniques (Safarali \& Hamidi, 2012). Therefore, when listeners know the context of a text or an utterance, the process is facilitated considerably because listeners can activate prior knowledge and makes the appropriate inferences essential to comprehending the message (Byrnes, 1984).Research shows that skilled listeners use more metacognitive strategies than their less-skilled counterparts (O'Malley \&Chamot, 1990; Vandergrift, 1997a).Several studies have shown that people can incidentally learn nonlocal dependencies (Creel et al., 2004; Gomez, 2002; Newport \&Aslin, 2004), the results of which would be rather challenging for chunking mechanisms.

\subsection{Research Questions}

The research questions for the present study were formulated as follows:

1. Does a chunk word have any impacts on listening comprehension?

2. In what ways can chunk words affect listening comprehension?

\subsection{Objectives of the Study}

Comprehension is what novice students are almost always looking for. To this end, they use chunk words amongst so many techniques to step in professional development. The aim is to find any probable impacts of chunk word on listening comprehension. To pave the way for all language students in general, and for novice ones in particular, it is hoped that this research can open a new route for English students. In addition, the output of this study can be a good ground for comparison with other researches in the same field.

One of the major goals of EFL instruction is to prepare students to understand the natural spontaneous speech of native speakers. It can be established through the knowledge of lexicon (Celece-Murcia 2001).

\section{Methodology}

\subsection{Research Design}

The study was carried out during the second semester of 2013 (summer term) in KISH language institute. The purpose of the study was to find out the effect of teaching multiword verbs on subjects' listening comprehension. This study was an attempt to provide answer to the following research question "Does learning multiword verbs have any significant effect on advanced students' listening comprehension"? The design required random selection and random assignment of the subjects into two groups: experimental and control. A pretest was administered to capture the initial differences between the groups in terms of knowledge of multiword. Due to the research questions the researcher selected a pre test - post test equivalent 
group design.

In this design the pretest was administered before the application of the treatments and the post test at the end of the treatment period. Gain scores may be compared and subjected to a test of the significance of the difference between means. Pretest score can also be used in the analysis of statistical control for any differences between the groups at the beginning of the study. The results of the pre test and post test in this study were correlated. In case of a statistically significant correlation, the null hypothesis would be refused or else confirmed.

\subsection{Participants}

The participants in this study were 60 advanced students from among 90 who took the test. They were randomly selected from KISH Language Institute. In order to select a homogeneous sample, the researcher prepared 50 multiple Questions and 50 multiword from advanced level of passages 1, 2 and TOEFL Longman and 50 Questions from listening comprehension from passages 1,2 and TOEFL Longman. To select the final subjects for the study, 60 students whose score fell on 0.5 standard deviations above and 0.5 standard deviations below the mean of 67.4 were selected. They were then randomly put into two groups of 30 , one experimental and the other control which were equal in number.

\subsection{Data Collection Instrument}

In order to select the teaching materials, some books

1. English Idioms In Use. Advanced, (Felicity, 2010).

2. Essential Idioms In English. Phrasal verbs and collocations (Robert J. Dixon, 2004).

3. Idioms and Phrasal verbs. (Ruth Gairn and Stuart Redman 2011) .

Were used. They consisted of some passages ten of which were selected for teaching since these passages contained multiword. They were used for the experimental group.

The experimental groups' material included passages containing multiword centered around common theme.

There were ten passages in the material, which took 20 sessions, 45 minutes each session per week.

In this experiment, the researcher tried to show the effectiveness of multiword on listening comprehension ability.

At the end of this period, a post test was given to subjects. All of the subjects who had taken the pretest were tested regarding their performance on multiword, and after this stage, the students were required to listen to a TOEFL Longman listening comprehension in phrasal verbs, idioms and collocations, which included some dialogues and texts. What was going to be tested was their listening ability and the impact of the instruction on their listening skills.

\subsection{Data Analysis}

After the result of multiple choice item were prepared, the subjects falling between +0.5 and -0.5 standard deviations with a mean of 64.4 were selected for the experimentation. Moreover, normality test, descriptive statistics, paired sample test and independent sample t-test were applied in order to estimate the effect of the treatment on students' language proficiency and listening comprehension.

The result of the data analysis are prepared and thoroughly discussed in the next section.

\section{Results}

Regarding the null hypothesis for this research which states that learning multiword verb has no effect on advanced students' listening comprehension, an attempt was made to test this significance.

To do so, the result of the students' performance on the two sets of tests (pre test and post test) had to be compared. If the comparison showed that their performance differed significantly, then the researcher would be able to claim that learning multiword verb (phrasal verbs and collocations) is effective in advanced students' listening comprehension. Therefore, the results of the performance of the subjects on the sets of tests were compared by using test of normality, descriptive statistics of pre-test, paired sample test and independent t-test.

\subsection{Test of Normality}

We use Kolmogorov-Smirnov to investigate about distribution of quantitative data. In this research, it is used in order to investigate about normality test. If it is, so we can use parametric statistics. The results of these tests were shown in table 1 and 2.

Table 1. Kolmogorov-Smirnov Test of experimental

\begin{tabular}{llll}
\hline & & $\begin{array}{l}\text { Pre experimental } \\
\text { Listening }\end{array}$ & $\begin{array}{l}\text { Post experimental } \\
\text { Listening }\end{array}$ \\
\hline $\mathrm{N}$ & 30 & 30 \\
Normal $\quad$ Mean & 39.1667 & 44.3667 \\
Parameters & Std. Deviation & 2.73021 & 2.84645 \\
Kolmogorov-Smirnov Z & 1.145 & .823 \\
Sig. (2-tailed) & .145 & .507 \\
\hline
\end{tabular}

Regarding the obtained the result of normality test, significant level is higher than 0.05 . Thus we can say the normality of test in experimental group is accepted and we use parametric statistic.

Table 2. Kolmogorov-Smirnov Test of control group

\begin{tabular}{llll}
\hline & & $\begin{array}{l}\text { Pre-test listening } \\
\text { control group }\end{array}$ & $\begin{array}{l}\text { Post-test listening } \\
\text { control group }\end{array}$ \\
\hline $\mathrm{N}$ & 30 & 30 \\
Normal & Mean & 38.6667 & 38.4333 \\
Parameters & Std. Deviation & 2.84464 & 3.53976 \\
Kolmogorov-Smirnov Z & 1.168 & 1.011 \\
Sig. (2-tailed) & .130 & .258 \\
\hline
\end{tabular}

Regarding the obtained the result of normality test, significant level is higher than 0.05 . Thus we can say the 
normality of test in control group is accepted and we use parametric statistic.

\subsection{Descriptive Statistics of Pre-Test and Post Test Experimental Group}

The result of this test is shown in table 3 .

Table 3. Descriptive statistics

\begin{tabular}{lllll}
\hline & Mean & N & SD & SEM \\
\hline Pair 1 Pre.ex.li & 39.16 & 30 & 2.73 & .4984 \\
Post.ex.li & 44.36 & 30 & 2.84 & .5196 \\
\hline
\end{tabular}

Note: Pre.ex. li= Pre experimental Listening, Pos.ex.li= Post experimental Listening.
Having established that there is a significant difference, the next step is to find out which set of scores is higher (Time 1 or Time 2). To do this, look in the first printout box, labeled descriptive statistics. This box gives us the Mean score at Time 1 was 39.1667 and the Mean score at Time 2 was 44.3667 .

\subsection{Paired Sample T-Test, Pre-Test and Post Test Experimental Group}

The result of this test is shown in table 4 .

Table 4. Paired samples test

\begin{tabular}{|c|c|c|c|c|c|c|c|c|}
\hline & \multicolumn{5}{|c|}{ Paired Differences } & \multirow{3}{*}{$\mathbf{t}$} & \multirow{3}{*}{ df } & \multirow{3}{*}{ Sig. (2tailed) } \\
\hline & \multirow{2}{*}{ Mean } & \multirow{2}{*}{ Std. deviation } & \multirow{2}{*}{ Std. Error Mean } & \multicolumn{2}{|c|}{$95 \%$ Confidence Interval of the difference } & & & \\
\hline & & & & lower & upper & & & \\
\hline $\begin{array}{l}\text { Pair1 } \\
\text { Pre.ex. li } \\
\text { Pos.ex.li }\end{array}$ & -5.2 & 1.49482 & 0.27292 & -5.75817 & -4.64183 & -19.054 & 29 & .000 \\
\hline
\end{tabular}

In the table labeled Paired samples test, we need to look in the last column, labeled Sig. (2-tailed) - this is our probability value. If this value is less than .05 (e.g. .04, .01, .001), we can conclude that there is a significant difference between our two scores. In the example given above, the probability value is .000 . This has actually been rounded down to three decimal places- it means that the actual probability value was less than .0005 . This value is substantially smaller than our specified alpha value of .05 . Therefore, we can conclude that there is a significant difference in the Statistics Test scores at Time 1 and at Time 2. Take note of the $t$ value and the degrees of freedom $(\mathrm{df}=29)$, as you will need these when you report your results. You should also note that the Mean increase 5.2 was with a 95\% Confidence Interval stretching from a Lower bound of -5.75817 to an Upper bound of -4.64183 .

\subsection{Descriptive Statistics Pre-Test and Post Test Control Group}

The result of this test is shown in table 5 .

Table 5. Descriptive statistics

\begin{tabular}{llllll}
\hline & Mean & N & $\begin{array}{l}\text { Std. } \\
\text { Deviation }\end{array}$ & $\begin{array}{l}\text { Std. Error } \\
\text { Mean }\end{array}$ \\
\hline \multirow{2}{*}{ Pair 1 } & Pr. Lis. Con. & 36.6667 & 30 & 2.84464 & .51936 \\
& Pos. Lis.Con. & 38.4333 & 30 & 3.53976 & .64627 \\
\hline
\end{tabular}

Having established that there isn't a significant difference, the next step is to find out which set of scores is higher (Time 1 or time 2 ). Table 5 gives the mean scores for each of the two sets of scores. In our case, the mean score at Time 1 was 36.6667 and the mean score at Time was 38.4333 .

\subsection{Paired Sample T-Test, Pre-Test and Post Test Control Group}

There is a step involved in interpreting the results of this analysis. The result of this test is shown in table 6 .

Table 6. Paired Samples Test

\begin{tabular}{|c|c|c|c|c|c|c|c|c|}
\hline & \multicolumn{5}{|c|}{ Paired Differences } & \multirow{3}{*}{$\mathbf{t}$} & \multirow{3}{*}{ df } & \multirow{3}{*}{ Sig. (2tailed) } \\
\hline & \multirow{2}{*}{ Mean } & \multirow{2}{*}{ Std. deviation } & \multirow{2}{*}{ Std. Error Mean } & \multicolumn{2}{|c|}{$\mathbf{9 5 \%}$ Confidence Interval of the difference } & & & \\
\hline & & & & lower & upper & & & \\
\hline $\begin{array}{l}\text { Pair1 } \\
\text { Pr. Lis. Con. } \\
\text { Pos. Lis.Con. }\end{array}$ & .23333 & 2.56882 & .46900 & -.72588 & 1.19255 & .498 & 29 & .623 \\
\hline
\end{tabular}

In the table labeled paired samples test, we need to look in the final column, labeled sig.(2-tailed) -this is probability value. If this value is less than. 05(e.g. .04, .01, .001), we can conclude that there is a significant difference between two scores. In the example given above, the probability value is .623. This value is substantially higher than our specified alpha value of .05 . Therefore, we can conclude that there isn't a significant difference in the of statistics test scores at time 1 and at Time 2. Take note of the $\mathbf{t}$ value 0.498 and the degrees of freedom ( $\mathrm{df}=29)$, as you will need these when you report your results. You should also note that the mean decrease was 0.23333 , with a 95 percent confidence interval stretching from a lower bound of -0.72588 to an Upper bound of 1.19255 . 


\subsection{Descriptive Statistics Pre-Test}

The result of this test is shown in table 7 .

Table 7. Group Statistics

\begin{tabular}{llllll}
\hline & group & N & Mean & $\begin{array}{l}\text { Std. } \\
\text { Deviation }\end{array}$ & $\begin{array}{l}\text { Std. Error } \\
\text { Mean }\end{array}$ \\
\hline \multirow{2}{*}{ PR.EX.L } & 1.00 & 30 & 39.1667 & 2.73021 & .49847 \\
& 2.00 & 30 & 38.6667 & 2.84464 & .51936 \\
\hline
\end{tabular}

Table 7 gives us the Mean score at Time 1 was 39.1667 and the Mean score at Time 2 was 38.6667.

\subsection{Independent Sample T-Test, Pre-Test Experimental and Control Group}

In this regard an independent t-test is run to compare the mean of experimental and control groups on the pre-test. The test observed value, 0.695 , at 58 degrees of freedom is lower than of critical value of t, i.e. 2 (table 8 ).

It can be concluded that there is not any significant deference between the two group mean on the pre-test. The two groups are homogenous in terms of their language proficiency prior to the administration of the treatment.

The F-test run to investigate the homogeneity of the variances of the two groups $(\mathrm{F}=0.025)$ has probability of 0.875 , indicates that the two groups are homogenous in terms of their variances. There for the equal variance estimates statistics are reported (table 8).

Table 8. Independent samples test: pre-test

\begin{tabular}{|c|c|c|c|c|c|c|c|c|}
\hline & & \multicolumn{2}{|c|}{ Levene's Test for Equality of Variances } & \multicolumn{5}{|c|}{ t-test for Equality of Means } \\
\hline & & $\mathbf{F}$ & Sig. & $\mathbf{t}$ & df & $\begin{array}{l}\text { Sig. } \\
\text { (2-tailed) }\end{array}$ & $\begin{array}{l}\text { Mean } \\
\text { Difference }\end{array}$ & $\begin{array}{l}\text { Std. Error } \\
\text { Difference }\end{array}$ \\
\hline \multirow{2}{*}{ PR.EX.L } & Equal variances assumed & .025 & .875 & .695 & 58 & .490 & .50000 & .71986 \\
\hline & Equal variances not assumed & & & .695 & 57.902 & .490 & .50000 & .71986 \\
\hline
\end{tabular}

\subsection{Descriptive Statistics Post-Test}

The result of this test is shown in table 9 .

Table 9. Group Statistics

\begin{tabular}{|c|c|c|c|c|c|}
\hline & group & $\mathbf{N}$ & Mean & Std. Deviation & Std. Error Mean \\
\hline \multirow{3}{*}{ Post.ex } & 1.00 & 30 & 44.3667 & 2.84645 & .51969 \\
\hline & & & & & \\
\hline & 2.00 & 30 & 28.8667 & 2.56949 & .46912 \\
\hline
\end{tabular}

Table 9 gives us the Mean score at Time 1 was 44.3667 and the Mean score at Time 2 was 28.8667.

\subsection{Independent Sample t-Test, Post-Test Experimental and Control Group}

In this regard an independent t-test is run to compare the mean of experimental and control groups on the post-test. The test observed value, 22.139, at 58 degrees of freedom is greater than of critical value of t, i.e. 2.02 (table 10).

It can be concluded that there is a significant deference between the two group mean on the post-test. The two groups aren't homogenous. The F-test run to investigate the homogeneity of the variances of the two groups $(\mathrm{F}=0.578)$ has probability of 0.005 , indicates that the two groups aren't homogenous in terms of their variances. There for the unequal variance estimates statistics are reported (table 10).

Table 10. Independent samples test: post-test

\begin{tabular}{|c|c|c|c|c|c|c|c|c|}
\hline & & \multicolumn{2}{|c|}{ Levene's Test for Equality of Variances } & \multicolumn{5}{|c|}{ t-test for Equality of Means } \\
\hline & & $\mathbf{F}$ & Sig. & $\mathbf{t}$ & df & $\begin{array}{l}\text { Sig. } \\
\text { (2-tailed) }\end{array}$ & $\begin{array}{l}\text { Mean } \\
\text { Difference }\end{array}$ & $\begin{array}{l}\text { Std. Error } \\
\text { Difference }\end{array}$ \\
\hline \multirow{2}{*}{ Pos.ex } & Equal variances assumed & .578 & .005 & 22.139 & 58 & .000 & 15.50000 & .70011 \\
\hline & Equal variances not assumed & & & 22.139 & 57.403 & .000 & 15.50000 & .70011 \\
\hline
\end{tabular}

\section{Discussion}

Due to the importance of multiword verbs in spoken and written language this research was conducted with the purpose of testing the null hypothesis claiming: learning multiword has no effect on advanced level students' listening comprehension ability. To test the stated hypothesis a group of 30 students were selected. The participants were advanced level students at passage $1 \& 2$ and TOEFL Longman listening comprehension in KISH English Language Institute. Before the inception of data collection,
English language test was administered to make sure that the selected subjects were all at the same level. The subjects were designed randomly to the Exp Time 1 and Time 2. Also, in order to ensure that the subjects are at the same level concerning the knowledge of multiword verbs, they were given a 50 multiple choice test (pretest), and then two different pamphlets were provided for 30 . The subjects in the experimental group were exposed to 10 passages containing phrasal verb and collocations. At the end of this period, learners were given a post test on multiword in order to see the achievement of 30 students and to determine 
whether this has a significant difference in their performance.

Then, some listening comprehension questions were administered to clarify the effect of learning multiword verbs on listening comprehension ability of subjects. The questions were based on the multiword verbs that they had learned during the period of instruction. The obtained results of normality test, descriptive statistics, paired sample test and independent sample t-test showed that it is impossible to reject the null hypothesis, which holds that learning multiword verbs has no significant effect on students' listening comprehension.

\section{Conclusion and Implication}

Vocabulary learning is a continuous task and it is a key component of language learning. The work of the scholars and practitioners shows that there has been a renewed interest in learning and teaching vocabulary (Maftoon, Hamidi \& Sarem, 2012). Words and particles can join together to make phrasal verbs and idioms. Therefore, this study tried to investigate whether the EFL students who learn multiword verbs, in addition to common verbs, phrasal verbs, collocation and idioms improved their listening comprehension. Because of the wide spread use of multiword units in everyday communication. This study is highly important to show the effect of multiword on advance level listening comprehension. So, the researcher hopes the findings of this study can help students improve the level of teaching English and promote knowledge of listening comprehension ability.

The use of multi words verbs (idioms, collocations and phrasal verbs) appears to be avoided in speech addressed to learner. On the other hand, idiomatic expressions aboard in movies, and on television. However, input without intersection and exercise is not sufficient for opportunities to clarify meaning and relieve feedback on use, which are essential for learning.

Thus, learners exposure to multiword verbs and idiomatic expression appears to be primarily in non-interactive situations, where there is no opportunity for negotiation of meaning. Most learners have little exposure to multiword verbs or idiom in interactive situation which are necessary for their learning. Multiword verbs have received inadequate attention in our text books and most of the students would like to resort to the avoidance strategy when confronted with them. However, multiword verbs are an integral part of the English language. So, the results obtained from this study: multiword verbs are highly effective in learners listening comprehension ability.

This study investigates the impact of multiword verbs on students' listening comprehension ability, these findings of this study led to several research areas.

1. It will be interested to compare different techniques in teaching and mastering multiword verbs.

2. A comparison of native speakers' speech and EFL learner speech can be done to see the frequency of the use of multiword verbs.

3. It is suggested to investigate the relationship between the knowledge of multiword verbs and learner productive skills.

4. The teaching of multiword verbs in interactive situations is the researchers last suggestion for further researcher.

\section{References}

[1] Byrnes, H. (1984). The Role of Listening Comprehension: $A$ Theoretical Base. Foreign Language Annals 17:317-29.

[2] Celce-Murcia, M. (2001). $3^{\text {rd }}$. Teaching English as a second or foreign language. Boston: Heinle and Heinle and publishing Co.

[3] Cowie, A.P, \& Mackin, R. (1983). Oxford Dictionary of current Idiomatic English. NolI . Ox ford university press.

[4] Creel, S. C., Newport, E. L., \&Aslin, R. N. (2004).Distant melodies: Statistical learning of nonadjacent dependencies in tone sequences. Journal of Experimental Psychology: Learning Memory, and Cognition,30, 1119-1130.

[5] Gobet et al. (2001). Chunking mechanisms in human learning. Trends in Cognitive Science, 5 (6), 236-243.

[6] Feigenbaum, E.A. (1963) The simulation of ver bal learning behavior. In Computers and Thought (Feigenbaum, E.A. and Feldman, J., eds),pp. 297-309, McGraw-Hill

[7] Feigenbaum, E.A. and Simon, H.A. (1984)EPAM-like models of recognition and learning. Cognit. Sci. 8, 305-336

[8] Feyten, C. M. (1991). The Power of Listening Ability: An Overlooked Dimension in Lan guage Acquisition. The Modern Language Journal, 75,173-80.

[9] Frank, M. C., Goldwater, S., Griffiths, T. L., \&Tenenbaum, J. B. (2010).Modeling human performance in statistical word segmenta tion.Cognition, 117, 107-125. doi:10.1016/j.cognition.2010.07.005

[10] French, RM., Addyman, C., \& Mareschal, D. (2001). TRACX: A Recognition-Based Connectionist Framework for Sequence Segmentation and Chunk Extraction. Psychological Review, 4, 614-636.

[11] Giroux, I., \& Rey, A. (2009).Lexical and sublexi cal units in speech perception. Cognitive Science: A Multidisciplinary Journal, 33, 260- 272.

[12] Gomez, R. L. (2002). Variability and detection of invariant structure. Psychological Science, 13, 431-436.

[13] Maftoon, P., Hamidi, H., \& Sarem, S. N. (2012). The effects of CALL on vocabulary learning: A case of Iranian intermediate EFL learners. Broad Research in Artificial Intelligence and Neuroscience, 3 (4), 19-30.

[14] Mendelsohn, D. (1998). Teaching Listening. Annual Review of Applied Linguistics 18:81- 101.

[15] Miller, G.A. (1956) The magical number seven, plus or minus two: some limits on our capacity for processing information. Psychol. Rev.63, 81-97 
[16] Newport, E. L., \&Aslin, R. N. (2004). Learning at a distance: 1. Statistical learning of non-adjacent dependencies. Cognitive Psychol ogy, 48, 127-162.

[17] O'Malley, J. M. \& A. U. Chamot (1990).Learning Strategies in Second Language Acquisition. Cambridge: Cambridge University Press.

[18] Perruchet, P., \& Desaulty, S. (2008). A role for backward transitional probabilities in word segmentation? Memory and Cognition, 36, 1299-1305.

[19] Rivers, w. m. (1982).Teaching For eign-Language Skills $\left(2^{\text {nd }}\right)$. Chicago: the univer sity of Chicago.
[20] Safarali, S. K., \& Hamidi, H. (2012). The impact of videos presenting speakers' gestures and facial clues on Iranian EFL learners' listening comprehension. International Journal of Ap plied Linguistics \& English Literature, 1 (6), 106-114.

[21] Vandergrift, L. (1997b). The Cinderella of Communication Strategies: Receptive Strategies in Interactive Listening. Modern Language Journal 81:494-505.

[22] Vandergrift, L. (2002). 'It was nice to see that our predictions were right': Developing Meta cognition in L2 Listening Comprehension. Ca nadian Modern Language Review, 58, 555-75. 